\title{
Uniformly closed replaced AKTT or *AKTT condition to get strong convergence theorems for a countable family of relatively quasi-nonexpansive mappings and systems of equilibrium problems
}

Jingling Zhang, Yongfu Su* and Qingqing Cheng

${ }^{*}$ Correspondence:

suyongfu@gmail.com

Department of Mathematics, Tianjin Polytechnic University, Tianjin, 300160, P.R. China

C2014 Zhang et al.; licensee Springer. This is an Open Access article distributed under the terms of the Creative Commons Attribution License (http://creativecommons.org/licenses/by/2.0), which permits unrestricted use, distribution, and reproduction in any medium, provided the original work is properly cited.

\begin{abstract}
The purpose of this paper is to construct a new iterative scheme and to get a strong convergence theorem for a countable family of relatively quasi-nonexpansive mappings and a system of equilibrium problems in a uniformly convex and uniformly smooth real Banach space using the properties of generalized $f$-projection operator. The notion of uniformly closed mappings is presented and an example will be given which is a countable family of uniformly closed relatively quasi-nonexpansive mappings but not a countable family of relatively nonexpansive mappings. Another example shall be given which is uniformly closed but does not satisfy condition AKTT and *AKTT. Our results can be applied to solve a convex minimization problem. In addition, this paper clarifies an ambiguity in a useful lemma. The results of this paper modify and improve many other important recent results.
\end{abstract}

MSC: $47 \mathrm{H} 05 ; 47 \mathrm{H} 09 ; 47 \mathrm{H} 10$

Keywords: relatively quasi-nonexpansive mapping; equilibrium problems; generalized $f$-projection operator; hybrid algorithm; uniformly closed mappings

\section{Introduction and preliminaries}

Let $E$ be a real Banach space and $C$ be a nonempty closed convex subset of $E$. A mapping $T: C \rightarrow C$ is called nonexpansive if

$$
\|T x-T y\| \leq\|x-y\|, \quad \forall x, y \in C .
$$

Let $E$ be a real Banach space and $C$ be a nonempty closed convex subset of $E$. A point $p \in C$ is said to be an asymptotic fixed point of $T$ if there exists a sequence $\left\{x_{n}\right\}_{n=0}^{\infty} \subset C$ such that $x_{n} \rightarrow p$ and $\lim _{n \rightarrow \infty}\left\|x_{n}-T x_{n}\right\|=0$. The set of asymptotic fixed point is denoted by $\hat{F}(T)$. We say that a mapping $T$ is relatively nonexpansive (see [1-4]) if the following conditions are satisfied:

(I) $F(T) \neq \emptyset$;

(II) $\phi(p, T x) \leq \phi(p, x), \forall x \in C, p \in F(T)$;

(III) $F(T)=\hat{F}(T)$. 
If $T$ satisfies (I) and (II), then $T$ is said to be relatively quasi-nonexpansive. It is easy to see that the class of relatively quasi-nonexpansive mappings contains the class of relatively nonexpansive mappings.

Let $E$ be a real Banach space. The modulus of smoothness of $E$ is the function $\rho_{E}$ : $[0, \infty) \rightarrow[0, \infty)$ defined by

$$
\rho_{E}(\tau)=\sup \left\{\frac{1}{2}(\|x+y\|+\|x-y\|)-1:\|x\| \leq 1,\|y\| \leq \tau\right\} .
$$

$E$ is uniformly smooth if and only if

$$
\lim _{\tau \rightarrow 0} \frac{\rho_{E} \tau}{\tau}=0
$$

Let $\operatorname{dim} E \geq 2$. The modulus of convexity of $E$ is the function $\delta_{E}(\epsilon):=\inf \left\{1-\left\|\frac{x+y}{2}\right\|:\|x\|=\right.$ $\|y\|=1 ; \epsilon=\|x-y\|\} . E$ is uniformly convex if for any $\epsilon \in(0,2]$, there exists $\delta=\delta(\epsilon)>0$ such that if $x, y \in E$ with $\|x\| \leq 1,\|y\| \leq 1$ and $\|x-y\| \geq \epsilon$, then $\left\|\frac{1}{2}(x+y)\right\| \leq 1-\delta$. Equivalently, $E$ is uniformly convex if and only if $\delta_{E}(\epsilon)>0$ for all $\epsilon \in(0,2]$. A normed space $E$ is called strictly convex if for all $x, y \in E, x \neq y,\|x\|=\|y\|=1$, we have $\|\lambda x+(1-\lambda) y\|<1, \forall \lambda \in(0,1)$.

Let $E^{*}$ be the dual space of $E$. We denote by $J$ the normalized duality mapping from $E$ to $2^{E^{*}}$ defined by

$$
J(x)=\left\{f \in E^{*}:\langle x, f\rangle=\|x\|^{2}=\|f\|^{2}\right\} .
$$

The following properties of $J$ are well known (see [5-7] for more details):

(1) If $E$ is uniformly smooth, then $J$ is norm-to-norm uniformly continuous on each bounded subset of $E$.

(2) If $E$ is reflexive, then $J$ is a mapping from $E$ onto $E^{*}$.

(3) If $E$ is smooth, then $J$ is single valued.

Throughout this paper, we denote by $\phi$ the functional on $E \times E$ defined by

$$
\phi(x, y)=\|x\|^{2}-2\langle x, J(y)\rangle+\|y\|^{2}, \quad \forall x, y \in E .
$$

Let $E$ be a smooth, strictly convex, and reflexive real Banach space and let $C$ be a nonempty closed convex subset of $E$. Following Alber [8], the generalized projection $\Pi_{C}$ from $E$ onto $C$ is defined by

$$
\Pi_{C}(x)=\underset{y \in C}{\arg \min } \phi(y, x), \quad \forall x \in E .
$$

The existence and uniqueness of $\Pi_{C}$ follows from the property of the functional $\phi(x, y)$ and strict monotonicity of the mapping $J$. It is obvious that

$$
(\|x\|-\|y\|)^{2} \leq \phi(x, y) \leq(\|x\|+\|y\|)^{2}, \quad \forall x, y \in E .
$$

Next, we recall the notion of generalized $f$-projection operator and its properties. Let $G: C \times E^{*} \rightarrow R \cup\{+\infty\}$ be a functional defined as follows:

$$
G(\xi, \varphi)=\|\xi\|^{2}-2\langle\xi, \varphi\rangle+\|\varphi\|^{2}+2 \rho f(\xi)
$$


where $\xi \in C, \varphi \in E^{*}, \rho$ is a positive number and $f: C \rightarrow R \cup\{+\infty\}$ is proper, convex, and lower semi-continuous. From the definitions of $G$ and $f$, it is easy to see the following properties:

(i) $G(\xi, \varphi)$ is convex and continuous with respect to $\varphi$ when $\xi$ is fixed;

(ii) $G(\xi, \varphi)$ is convex and lower semi-continuous with respect to $\xi$ when $\varphi$ is fixed.

Definition 1.1 [9] Let $E$ be a real Banach space with its dual $E^{*}$. Let $C$ be a nonempty, closed, and convex subset of $E$. We say that $\Pi_{C}^{f}: E^{*} \rightarrow 2^{C}$ is a generalized $f$-projection operator if

$$
\Pi_{C}^{f} \varphi=\left\{u \in C: G(u, \varphi)=\inf _{\xi \in C} G(\xi, \varphi)\right\}, \quad \forall \varphi \in E^{*} .
$$

For the generalized $f$-projection operator, Wu and Huang [9] proved in the following theorem some basic properties.

Lemma 1.2 [9] Let E be a real reflexive Banach space with its dual $E^{*}$. Let $C$ be a nonempty, closed, and convex subset of $E$. Then the following statements hold:

(i) $\Pi_{C}^{f}$ is a nonempty closed convex subset of $C$ for all $\varphi \in E^{*}$.

(ii) If $E$ is smooth, then for all $\varphi \in E^{*}, x \in \Pi_{C}^{f} \varphi$ if and only if

$$
\langle x-y, \varphi-J x\rangle+\rho f(y)-\rho f(x) \geq 0, \quad \forall y \in C .
$$

(iii) If $E$ is strictly convex and $f: C \rightarrow R \cup\{+\infty\}$ is positive homogeneous (i.e., $f(t x)=t f(x)$ for all $t>0$ such that $t x \in C$ where $x \in C)$, then $\Pi_{C}^{f}$ is a single-valued mapping.

Fan et al. [10] showed that the condition $f$ is positive homogeneous which appeared in Lemma 1.2 can be removed.

Lemma 1.3 [10] Let E be a real reflexive Banach space with its dual $E^{*}$ and $C$ a nonempty, closed, and convex subset of $E$. Then if $E$ is strictly convex, then $\Pi_{C}^{f}$ is a single-valued mapping.

Recall that $J$ is a single-valued mapping when $E$ is a smooth Banach space. There exists a unique element $\varphi \in E^{*}$ such that $\varphi=J x$ for each $x \in E$. This substitution in (1.3) gives

$$
G(\xi, J x)=\|\xi\|^{2}-2\langle\xi, J x\rangle+\|x\|^{2}+2 \rho f(\xi)
$$

Now, we consider the second generalized $f$-projection operator in a Banach space.

Definition 1.4 [11] Let $E$ be a real Banach space and $C$ a nonempty, closed, and convex subset of $E$. We say that $\Pi_{C}^{f}: E \rightarrow 2^{C}$ is a generalized $f$-projection operator if

$$
\Pi_{C}^{f} x=\left\{u \in C: G(u, J x)=\inf _{\xi \in C} G(\xi, J x)\right\}, \quad \forall x \in E .
$$

Obviously, the definition of relatively quasi-nonexpansive mapping $T$ is equivalent to

(1) $F(T) \neq \emptyset$;

(2) $G(p, J T x) \leq G(p, J x), \forall x \in C, p \in F(T)$. 
Lemma 1.5 [12] Let E be a Banach space and $: E \rightarrow R \cup\{+\infty\}$ be a lower semi-continuous convex functional. Then there exist $x \in E^{*}$ and $\alpha \in R$ such that

$$
f(x) \geq\left\langle x, x^{*}\right\rangle+\alpha, \quad \forall x \in E .
$$

We know that the following lemmas hold for operator $\Pi_{C}^{f}$

Lemma 1.6 [13] Let C be a nonempty, closed, and convex subset of a smooth and reflexive Banach space E. Then the following statements hold:

(i) $\Pi_{C}^{f}$ is a nonempty, closed, and convex subset of $C$ for all $x \in E$;

(ii) for all $x \in E, \hat{x} \in \Pi_{C}^{f} x$ if and only if

$$
\langle\hat{x}-y, J x-J \hat{x}\rangle+\rho f(y)-\rho f(x) \geq 0, \quad \forall y \in C ;
$$

(iii) if $E$ is strictly convex, then $\Pi_{C}^{f} x$ is a single-valued mapping.

Lemma 1.7 [13] Let C be a nonempty, closed, and convex subset of a smooth and reflexive Banach space E. Let $x \in E$ and $\hat{x} \in \Pi_{C}^{f} x$. Then

$$
\phi(y, \hat{x})+G(\hat{x}, J x) \leq G(y, J x), \quad \forall y \in C .
$$

The fixed points set $F(T)$ of a relatively quasi-nonexpansive mapping is closed convex as given in the following lemma.

Lemma 1.8 $[14,15]$ Let $C$ be a nonempty closed convex subset of a smooth, uniformly convex Banach space E. Let $T$ be a closed relatively quasi-nonexpansive mapping of $C$ into itself. Then $F(T)$ is closed and convex.

Also, this following lemma will be used in the sequel.

Lemma 1.9 [16] Let $C$ be a nonempty closed convex subset of a smooth, uniformly convex Banach space E. Let $\left\{x_{n}\right\}_{n=0}^{\infty}$ and $\left\{y_{n}\right\}_{n=0}^{\infty}$ be sequences in E such that either $\left\{x_{n}\right\}_{n=0}^{\infty}$ or $\left\{y_{n}\right\}_{n=0}^{\infty}$ is bounded. If $\lim _{n \rightarrow \infty} \phi\left(x_{n}, y_{n}\right)=0$, then $\lim _{n \rightarrow \infty}\left\|x_{n}-y_{n}\right\|=0$.

Lemma 1.10 [17] Let $p>1$ and $r>0$ be two fixed real numbers. Then a Banach space $X$ is uniformly convex if and only if there is a continuous, strictly increasing and convex function $g: R^{+} \rightarrow R^{+}, g(0)=0$, such that

$$
\|\lambda x+(1-\lambda) y\|^{p} \leq \lambda\|x\|^{p}+(1-\lambda)\|y\|^{p}-W_{p}(\lambda) g(\|x-y\|)
$$

for all $x, y \in B_{r}$ and $0 \leq \lambda \leq 1$, where $W_{p}(\lambda)=\lambda(1-\lambda)^{p}+\lambda^{p}(1-\lambda)$.

Remark We can see from the Lemma 1.10 that the function $g$ has no relation with the selection of $x, y$ and $\lambda$. However, the key point above, in the process of generalization and application about this lemma, has been ambiguous gradually. For instance, the following lemma states that the function $g$ has something to do with $\lambda$, which always leads to failure in the proof. 
Lemma (stated in [11, Lemma 2.10]) Let E be a uniformly convex real Banach space. For arbitrary $r>0$, let $B_{r}(0):=\{x \in E:\|x\| \leq r\}$ and $\lambda \in[0,1]$. Then there exists a continuous strictly increasing convex function

$$
g:[0,2 r] \rightarrow R, \quad g(0)=0
$$

such that for every $x, y \in B_{r}(0)$, the following inequality holds:

$$
\|\lambda x+(1-\lambda) y\|^{2} \leq \lambda\|x\|^{2}+(1-\lambda)\|y\|^{2}-\lambda(1-\lambda) g(\|x-y\|) .
$$

Let $F$ be a bifunction of $C \times C$ into $R$. The equilibrium problem is to find $x^{*} \in C$ such that $F\left(x^{*}, y\right) \geq 0$, for all $y \in C$. We shall denote the solutions set of the equilibrium problem by $E P(F)$. Numerous problems in physics, optimization, and economics reduce to find a solution of equilibrium problem. The equilibrium problems include fixed point problems, optimization problems, and variational inequality problems as special cases.

For solving the equilibrium problem for a bifunction $F: C \times C \rightarrow R$, let us assume that $F$ satisfies the following conditions:

(A1) $F(x, x)=0$ for all $x \in C$;

(A2) $F$ is monotone, i.e., $F(x, y)+F(y, x) \leq 0$ for all $x, y \in C$;

(A3) for each $x, y \in C, \lim _{t \rightarrow 0} F(t z+(1-t) x, y) \leq F(x, y)$;

(A4) for each $x \in C, y \mapsto F(x, y)$ is convex and lower semi-continuous.

Lemma 1.11 [18] Let $C$ be a nonempty closed convex subset of a smooth, strictly convex and reflexive Banach space $E$ and let $F$ be a bifunction of $C \times C$ into $R$ satisfying (A1)-(A4). Let $r>0$ and $x \in E$. Then there exists $z \in C$ such that

$$
F(z, y)+\frac{1}{r}\langle y-z, J z-J x\rangle \geq 0, \quad \forall y \in K .
$$

Lemma 1.12 [19] Let $C$ be a nonempty closed convex subset of a smooth, strictly convex and reflexive Banach space $E$. Assume that $F: C \times C \rightarrow R$ satisfies (A1)-(A4). For $r>0$ and $x \in E$, define a mapping $T_{r}^{F}: E \rightarrow C$ as follows:

$$
T_{r}^{F}(x)=\left\{z \in C: F(z, y)+\frac{1}{r}\langle y-z, J z-J x\rangle \geq 0, \forall y \in C\right\}
$$

for all $z \in E$. Then the following hold:

(1) $T_{r}^{F}$ is single valued;

(2) $T_{r}^{F}$ is a firmly nonexpansive-type mapping, i.e., for any $x, y \in E$,

$$
\left\langle T_{r}^{F} x-T_{r}^{F} y, J T_{r}^{F} x-J T_{r}^{F} y\right\rangle \leq\left\langle T_{r}^{F} x-T_{r}^{F} y, J x-J y\right\rangle ;
$$

(3) $F\left(T_{r}^{F}\right)=E P(F)$;

(4) $E P(F)$ is closed and convex.

Lemma 1.13 [19] Let $C$ be a nonempty closed convex subset of a smooth, strictly convex and reflexive Banach space E. Assume that $F: C \times C \rightarrow R$ satisfies (A1)-(A4) and let $r>0$. Then for each $x \in E$ and $q \in F\left(T_{r}^{F}\right)$,

$$
\phi\left(q, T_{r}^{F} x\right)+\phi\left(T_{r}^{F} x, x\right) \leq \phi(q, x) .
$$


Let $\left\{T_{n}\right\}$ be a sequence of mappings from $C$ into $E$, where $C$ is a nonempty closed convex subset of a real Banach space $E$. For a subset $B$ of $C$, we say that

(i) $\left(\left\{T_{n}\right\}, B\right)$ satisfies condition AKTT (see [15]) if

$$
\sum_{n=1}^{\infty} \sup \left\{\left\|T_{n+1} x-T_{n} x\right\|: x \in B\right\}<\infty
$$

(ii) $\left(\left\{T_{n}\right\}, B\right)$ satisfies condition *AKTT (see [15]) if

$$
\sum_{n=1}^{\infty} \sup \left\{\left\|J T_{n+1} x-J T_{n} x\right\|: x \in B\right\}<\infty
$$

Recently, Shehu [11] proved strong convergence theorems for approximation of common element of set of common fixed points of countably infinite family of relatively quasinonexpansive mappings and set of common solutions to a system of equilibrium problems in a uniformly convex and uniformly smooth real Banach space using the properties of generalized $f$-projection operator. The author obtained the following theorem.

Theorem 1.14 [11] Let E be a uniformly convex real Banach space which is also uniformly smooth. Let $C$ be a nonempty closed convex subset of $E$. For each $k=1,2, \ldots, m$, let $F_{k}$ be a bifunction from $C \times C$ satisfying (A1)-(A4) and let $\left\{T_{n}\right\}_{n=1}^{\infty}$ be an infinite family of relatively quasi-nonexpansive mappings of $C$ into itself such that $F:=\left(\bigcap_{n=1}^{\infty} F\left(T_{n}\right)\right) \cap\left(\bigcap_{k=1}^{m} E P\left(F_{k}\right)\right) \neq$ $\emptyset$. Let $f: E \rightarrow R$ be a convex and lower semi-continuous mapping with $C \subset \operatorname{int}(D(f))$ and suppose $\left\{x_{n}\right\}_{n=0}^{\infty}$ is iteratively generated by $x_{0} \in C, C_{1}=C, x_{1}=\Pi_{C_{1}}^{f} x_{0}$,

$$
\left\{\begin{array}{l}
y_{n}=J^{-1}\left(\alpha_{n} J x_{n}+\left(1-\alpha_{n}\right) J T_{n} x_{n}\right), \\
u_{n}=T_{r_{m, n}}^{F_{m}} T_{r_{m-1, n}}^{F_{m-1}} \cdots T_{r_{2, n}}^{F_{2}} T_{r_{1, n}}^{F_{1}} y_{n}, \\
C_{n+1}=\left\{w \in C_{n}: G\left(w, J u_{n}\right) \leq G\left(w, J x_{n}\right)\right\} \\
x_{n+1}=\Pi_{C_{n+1}}^{f} x_{0}, \quad n \geq 1,
\end{array}\right.
$$

where $J$ is the duality mapping on E. Suppose $\left\{\alpha_{n}\right\}_{n=1}^{\infty}$ is a sequence in $(0,1)$ such that $\liminf _{n \rightarrow \infty} \alpha_{n}\left(1-\alpha_{n}\right)>0\left\{r_{k, n}\right\}_{n=1}^{\infty} \subset(0, \infty)(k=1,2, \ldots, m)$ satisfying $\liminf _{n \rightarrow \infty} r_{k, n}>0$ $(k=1,2, \ldots, m)$. Suppose that for each bounded subset $B$ of $C$, the ordered pair $\left(\left\{T_{n}\right\}, B\right)$ satisfies either condition AKTT or condition *AKTT. Let $T$ be the mapping from $C$ into $E$ defined by $T x=\lim _{n \rightarrow \infty} T_{n} x$ for all $x \in C$ and suppose that $T$ is closed and $F(T)=\bigcap_{n=1}^{\infty} F\left(T_{n}\right)$. Then $\left\{x_{n}\right\}_{n=0}^{\infty}$ converges strongly to $\Pi_{F}^{f} x_{0}$.

In this paper we will construct a new iterative scheme and will get strong convergence theorem for a countable family of relatively quasi-nonexpansive mappings and a system of equilibrium problems in a uniformly convex and uniformly smooth real Banach space using the properties of generalized $f$-projection operator. The notion of uniformly closed mappings is presented and an example will be given which is a countable family of uniformly closed relatively quasi-nonexpansive mappings but not a countable family of relatively nonexpansive mappings. Another example shall be given which is uniformly closed but not satisfy condition AKTT and *AKTT. 


\section{Main results}

Now, we shall first introduce the notion of uniformly closed mappings and give an example which is a countable family of uniformly closed relatively quasi-nonexpansive mappings but not a countable family of relatively nonexpansive mappings in the sense of $G$. Another example shall be given which is uniformly closed but not satisfy condition AKTT and *AKTT.

Definition 2.1 Let $E$ be a Banach space, $C$ be a nonempty closed convex subset of $E$. Let $\left\{T_{n}\right\}_{n=1}^{\infty}: C \rightarrow E$ be a sequence of mappings of $C$ into $E$ such that $\bigcap_{n=1}^{\infty} F\left(T_{n}\right)$ is nonempty. $\left\{T_{n}\right\}_{n=1}^{\infty}$ is said to be uniformly closed, if $p \in \bigcap_{n=1}^{\infty} F\left(T_{n}\right)$, whenever $\left\{x_{n}\right\} \subset C$ converges strongly to $p$ and $\left\|x_{n}-T_{n} x_{n}\right\| \rightarrow 0$ as $n \rightarrow \infty$.

Example 1 Let $E=l^{2}$, where

$$
\begin{aligned}
& l^{2}=\left\{\xi=\left(\xi_{1}, \xi_{2}, \xi_{3}, \ldots, \xi_{n}, \ldots\right): \sum_{n=1}^{\infty}\left|\xi_{n}\right|^{2}<\infty\right\}, \\
& \|\xi\|=\left(\sum_{n=1}^{\infty}\left|\xi_{n}\right|^{2}\right)^{\frac{1}{2}}, \quad \forall \xi \in l^{2}, \\
& \langle\xi, \eta\rangle=\sum_{n=1}^{\infty} \xi_{n} \eta_{n}, \quad \forall \xi=\left(\xi_{1}, \xi_{2}, \xi_{3}, \ldots, \xi_{n}, \ldots\right), \eta=\left(\eta_{1}, \eta_{2}, \eta_{3}, \ldots, \eta_{n}, \ldots\right) \in l^{2} .
\end{aligned}
$$

It is well known that $l^{2}$ is a Hilbert space, so that $\left(l^{2}\right)^{*}=l^{2}$. Let $\left\{x_{n}\right\} \subset E$ be a sequence defined by

$$
\begin{aligned}
& x_{0}=(1,0,0,0, \ldots), \\
& x_{1}=(1,1,0,0, \ldots), \\
& x_{2}=(1,0,1,0,0, \ldots), \\
& x_{3}=(1,0,0,1,0,0, \ldots), \\
& \ldots \\
& x_{n}=\left(\xi_{n, 1}, \xi_{n, 2}, \xi_{n, 3}, \ldots, \xi_{n, k}, \ldots\right) \\
& \ldots,
\end{aligned}
$$

where

$$
\xi_{n, k}= \begin{cases}1, & \text { if } k=1, n+1, \\ 0, & \text { if } k \neq 1, k \neq n+1,\end{cases}
$$

for all $n \geq 1$.

Define a countable family of mappings $T_{n}: E \rightarrow E$ as follows:

$$
T_{n}(x)= \begin{cases}\frac{n}{n+1} x_{n}, & \text { if } x=x_{n}, \\ -x, & \text { if } x \neq x_{n},\end{cases}
$$

for all $n \geq 0$. 
Conclusion $2.2\left\{T_{n}\right\}_{n=0}^{\infty}$ has a unique fixed point 0 , that is, $F\left(T_{n}\right)=\{0\} \neq \emptyset, \forall n \geq 0$.

Proof The conclusion is obvious.

Let $\left\{T_{n}\right\}_{n=1}^{\infty}$ be a countable family of quasi-relatively quasi-nonexpansive mappings, if

$$
\bigcap_{n=0}^{\infty} F\left(T_{n}\right)=\widehat{F}\left(\left\{T_{n}\right\}_{n=0}^{\infty}\right),
$$

the $\left\{T_{n}\right\}_{n=1}^{\infty}$ is said to be a countable family of relatively nonexpansive mappings in the sense of functional $G$, where

$$
\widehat{F}\left(\left\{T_{n}\right\}_{n=0}^{\infty}\right)=\left\{p \in C: \exists x_{n} \rightarrow p,\left\|x_{n}-T_{n} x_{n}\right\| \rightarrow 0, x_{n} \in C\right\}
$$

is said to be the asymptotic fixed point set of $\left\{T_{n}\right\}_{n=1}^{\infty}$.

Conclusion 2.3 $\left\{T_{n}\right\}_{n=0}^{\infty}$ is a countable family of relatively quasi-nonexpansive mappings but not a countable family of relatively nonexpansive mappings in the sense of functional G.

Proof By Conclusion 2.2, we only need to show that $G\left(0, J T_{n} x\right) \leq G(0, J x), \forall x \in E$. Note that $E=l^{2}$ is a Hilbert space, for any $n \geq 0$ we can derive

$$
\begin{gathered}
G\left(0, J T_{n} x\right) \leq G(0, J x) \quad \forall x \in E \\
\Leftrightarrow \quad \phi\left(0, T_{n} x\right) \leq \phi(0, x) \\
\Leftrightarrow \quad\left\|0-T_{n} x\right\|^{2} \leq\|0-x\|^{2} \\
\Leftrightarrow \quad\left\|T_{n} x\right\|^{2} \leq\|x\|^{2} .
\end{gathered}
$$

It is obvious that $\left\{x_{n}\right\}$ converges weakly to $x_{0}=(1,0,0, \ldots)$, and

$$
\left\|x_{n}-T_{n} x_{n}\right\|=\left\|\frac{n}{n+1} x_{n}-x_{n}\right\|=\frac{1}{n+1}\left\|x_{n}\right\| \rightarrow 0
$$

as $n \rightarrow \infty$, so $x_{0}$ is an asymptotic fixed point of $\left\{T_{n}\right\}_{n=0}^{\infty}$. Joining with Conclusion 2.2, we can obtain $\bigcap_{n=0}^{\infty} F\left(T_{n}\right) \neq \widehat{F}\left(\left\{T_{n}\right\}_{n=0}^{\infty}\right)$.

Thus, $\left\{T_{n}\right\}_{n=0}^{\infty}$ is a countable family of relatively quasi-nonexpansive mappings but not a countable family of relatively nonexpansive mappings in the sense of $G$.

Conclusion 2.4 $\left\{T_{n}\right\}_{n=0}^{\infty}$ is a countable family of uniformly closed relatively quasinonexpansive mappings in the sense of functional $G$.

Proof In fact, for any strong convergent sequence $\left\{z_{n}\right\} \subset E$ such that $z_{n} \rightarrow z_{0}$ and $\| z_{n}-$ $T_{n} z_{n} \| \rightarrow 0$ as $n \rightarrow \infty$, there exists a sufficiently large nature number $N$, such that $z_{n} \neq x_{m}$ for any $n, m>N$ (since $x_{n}$ is not a Cauchy sequence it cannot converge to any element in $E$ ). Then $T_{n} z_{n}=-z_{n}$ for $n>N$, it follows from $\left\|z_{n}-T_{n} z_{n}\right\| \rightarrow 0$ that $2 z_{n} \rightarrow 0$ and hence $z_{n} \rightarrow z_{0}=0$. 
Therefore, $\left\{T_{n}\right\}_{n=0}^{\infty}$ is a countable family of uniformly closed relatively quasi-nonexpansive mappings but not a countable family of relatively nonexpansive mappings in the sense of functional $G$.

Now, we give an example which is a countable family of uniformly closed quasinonexpansive mappings but not satisfied condition AKTT and *AKTT.

Example 2 Let $X=\Re^{2}$. For any complex number $x=r e^{i \theta} \in X$, define a countable family of quasi-nonexpansive mappings as follows:

$$
T_{n}: r e^{i \theta} \rightarrow r e^{i\left(\theta+n \frac{\pi}{2}\right)}, \quad n=1,2,3, \ldots
$$

Proof It is easy to see that $\bigcap_{n=1}^{\infty} F\left(T_{n}\right)=\{0\}$. We first prove that $\left\{T_{n}\right\}$ is uniformly closed. In fact, for any strong convergent sequence $\left\{x_{n}\right\} \subset X$ such that $x_{n} \rightarrow x_{0}$ and $\left\|x_{n}-T_{n} x_{n}\right\| \rightarrow 0$ as $n \rightarrow \infty$, there must be $x_{0}=0 \in \bigcap_{n=1}^{\infty} F\left(T_{n}\right)$. Otherwise, if $x_{n} \rightarrow x_{0} \neq 0$, and

$$
\left\|x_{4 n+1}-T_{4 n+1} x_{4 n+1}\right\| \rightarrow 0
$$

since $T_{1}$ is continuous, we have

$$
\begin{aligned}
& \left\|x_{4 n+1}-T_{4 n+1} x_{4 n+1}\right\| \\
& \quad=\left\|x_{4 n+1}-T_{1} x_{4 n+1}\right\| \rightarrow\left\|x_{0}-T_{1} x_{0}\right\| \neq 0 .
\end{aligned}
$$

This is a contradiction. Therefore, $\left\{T_{n}\right\}$ is uniformly closed.

Besides, take any $x=r e^{i \theta} \neq 0$. For any $n$ by the definition of $T_{n}$, we have

$$
\left\|T_{n} x-T_{n+1} x\right\|=\left\|r e^{\frac{\pi i}{2}}\right\|=r>0
$$

and

$$
\left\|J T_{n} x-J T_{n+1} x\right\|=\left\|r e^{\frac{\pi i}{2}}\right\|=r>0 .
$$

That is to say, $\left\{T_{n}\right\}$ does not satisfied condition AKTT and *AKTT.

Now we are in a position to present our main theorems.

Theorem 2.5 Let $\left\{T_{n}\right\}_{n=1}^{\infty}$ be a countable family of uniformly closed relatively quasinonexpansive mappings of $C$ into itself and other conditions are the same as Theorem 1.14 except for condition AKTT, * AKTT and condition 'Let $T$ be the mapping from $C$ into $E$ defined by $T x=\lim _{n \rightarrow \infty} T_{n} x$ for all $x \in C$ and suppose that $T$ is closed and $F(T)=\bigcap_{n=1}^{\infty} F\left(T_{n}\right)$. Then the sequence $\left\{x_{n}\right\}_{n=0}^{\infty}$ generated by (1.5) converges strongly to $\Pi_{F}^{f} x_{0}$.

Proof We first show that $C_{n}, \forall n \geq 1$, is closed and convex. It is obvious that $C_{1}=C$ is closed and convex. Suppose that $C_{n}$ is closed convex for some $n>1$. From the definition of $C_{n+1}$, we have $z \in C_{n+1}$ implies $G\left(z, J u_{n}\right) \leq G\left(z, J x_{n}\right)$. This is equivalent to

$$
2\left(\left\langle z, J x_{n}\right\rangle-\left\langle z, J u_{n}\right\rangle\right) \leq\left\|x_{n}\right\|^{2}-\left\|u_{n}\right\|^{2} .
$$


This implies that $C_{n+1}$ is closed convex for the same $n>1$. Hence, $C_{n}$ is closed and convex for all $n \geq 1$. This shows that $\Pi_{C_{n+1}}^{f} x_{0}$ is well defined for all $n \geq 0$.

By taking $\theta_{n}^{k}=T_{r_{k, n}}^{F_{k}} T_{r_{k-1, n}}^{F_{k-1}} \ldots T_{r_{2, n}}^{F_{2}} T_{r_{1, n}}^{F_{1}}, k=1,2, \ldots, m$ and $\theta_{n}^{0}=I$ for all $n \geq 1$, we obtain $u_{n}=\theta_{n}^{m} y_{n}$.

We next show that $F \subset C_{n}, \forall n \geq 1$. From Lemma 1.12, one sees that $T_{r_{k, n}}^{F_{k}}, k=1,2, \ldots, m$, is relatively nonexpansive mapping. For $n=1$, we have $F \subset C=C_{1}$. Now, assume that $F \subset C_{n}$ for some $n \geq 2$. Then for each $x^{*} \in F$, we obtain

$$
\begin{aligned}
G\left(x^{*}, J u_{n}\right)= & G\left(x^{*}, J \theta_{n}^{m} y_{n}\right) \leq G\left(x^{*}, J y_{n}\right) \\
= & G\left(x^{*},\left(\alpha_{n} J x_{n}+\left(1-\alpha_{n}\right) J T_{n} x_{n}\right)\right) \\
= & \left\|x^{*}\right\|^{2}-2 \alpha_{n}\left\langle x^{*}, J x_{n}\right\rangle-2\left(1-\alpha_{n}\right)\left(x^{*}, J T_{n} x_{n}\right\rangle \\
& +\left\|\alpha_{n} J x_{n}+\left(1-\alpha_{n}\right) J T_{n} x_{n}\right\|^{2}+2 \rho f\left(x^{*}\right) \\
\leq & \left\|x^{*}\right\|^{2}-2 \alpha_{n}\left\langle x^{*}, J x_{n}\right\rangle-2\left(1-\alpha_{n}\right)\left(x^{*}, J T_{n} x_{n}\right\rangle \\
& +\alpha_{n}\left\|J x_{n}\right\|^{2}+\left(1-\alpha_{n}\right)\left\|J T_{n} x_{n}\right\|^{2}+2 \rho f\left(x^{*}\right) \\
= & \alpha_{n} G\left(x^{*}, J x_{n}\right)+\left(1-\alpha_{n}\right) G\left(x^{*}, J T_{n} x_{n}\right) \leq G\left(x^{*}, J x_{n}\right) .
\end{aligned}
$$

So, $x^{*} \in C_{n}$. This implies that $F \subset C_{n}, \forall n \geq 1$ and the sequence $\left\{x_{n}\right\}_{n=0}^{\infty}$ generated by (1.5) is well defined.

We now show that $\lim _{n \rightarrow \infty} G\left(x_{n}, J x_{0}\right)$ exists. Since $f: E \rightarrow R$ is a convex and lower semicontinuous, applying Lemma 1.5 , we see that there exist $u^{*} \in E^{*}$ and $\alpha \in R$ such that

$$
f(y) \geq\left\langle y, u^{*}\right\rangle+\alpha, \quad \forall y \in E .
$$

It follows that

$$
\begin{aligned}
G\left(x_{n}, J x_{0}\right) & =\left\|x_{n}\right\|^{2}-2\left\langle x_{n}, J x_{0}\right\rangle+\left\|x_{0}\right\|^{2}+2 \rho f\left(x_{n}\right) \\
& \geq\left\|x_{n}\right\|^{2}-2\left\langle x_{n}, J x_{0}\right\rangle+\left\|x_{0}\right\|^{2}+2 \rho\left\langle x_{n}, u^{*}\right\rangle+2 \rho \alpha \\
& =\left\|x_{n}\right\|^{2}-2\left\langle x_{n}, J x_{0}-\rho u^{*}\right\rangle+\left\|x_{0}\right\|^{2}+2 \rho \alpha \\
& \geq\left\|x_{n}\right\|^{2}-2\left\|x_{n}\right\|\left\|J x_{0}-\rho u^{*}\right\|+\left\|x_{0}\right\|^{2}+2 \rho \alpha \\
& =\left(\left\|x_{n}\right\|-\left\|J x_{0}-\rho u^{*}\right\|\right)^{2}+\left\|x_{0}\right\|^{2}-\left\|J x_{0}-\rho u^{*}\right\|^{2}+2 \rho \alpha .
\end{aligned}
$$

Since $x_{n}=\Pi_{C_{n}}^{f} x_{0}$, it follows from (2.2) that

$$
G\left(x^{*}, J x_{0}\right) \geq G\left(x_{n}, J x_{0}\right) \geq\left(\left\|x_{n}\right\|-\left\|J x_{0}-\rho u^{*}\right\|\right)^{2}+\left\|x_{0}\right\|^{2}-\left\|J x_{0}-\rho u^{*}\right\|^{2}+2 \rho \alpha
$$

for each $x^{*} \in F(T)$. This implies that $\left\{x_{n}\right\}_{n=1}^{\infty}$ is bounded and so is $\left\{G\left(x_{n}, J x_{0}\right)\right\}_{n=0}^{\infty}$. By the construction of $C_{n}$, we have $C_{m} \subset C_{n}$ and $x_{m}=\Pi_{C_{m}}^{f} x_{0} \in C_{n}$ for any positive integer $m \geq n$. It then follows from Lemma 1.7 that

$$
\phi\left(x_{m}, x_{n}\right)+G\left(x_{n}, J x_{0}\right) \leq G\left(x_{m}, J x_{0}\right) .
$$


It is obvious that

$$
\phi\left(x_{m}, x_{n}\right) \geq\left(\left\|x_{m}\right\|-\left\|x_{n}\right\|\right)^{2} \geq 0 .
$$

In particular,

$$
\phi\left(x_{n+1}, x_{n}\right)+G\left(x_{n}, J x_{0}\right) \leq G\left(x_{n+1}, J x_{0}\right)
$$

and

$$
\phi\left(x_{n+1}, x_{n}\right) \geq\left(\left\|x_{n+1}\right\|-\left\|x_{n}\right\|\right)^{2} \geq 0,
$$

and so $\left\{G\left(x_{n}, J x_{0}\right)\right\}_{n=0}^{\infty}$ is nondecreasing. It follows that the limit of $\left\{G\left(x_{n}, J x_{0}\right)\right\}_{n=0}^{\infty}$ exists.

By the fact that $C_{m} \subset C_{n}$ and $x_{m}=\Pi_{C_{m}}^{f} x_{0} \in C_{n}$ for any positive integer $m \geq n$, we obtain

$$
\phi\left(x_{m}, u_{n}\right) \leq \phi\left(x_{m}, x_{n}\right)
$$

Now, (2.3) implies that

$$
\phi\left(x_{m}, u_{n}\right) \leq \phi\left(x_{m}, x_{n}\right) \leq G\left(x_{m}, J x_{0}\right)-G\left(x_{n}, J x_{0}\right) .
$$

Taking the limit as $m, n \rightarrow \infty$ in (2.4), we obtain

$$
\lim _{n \rightarrow \infty} \phi\left(x_{m}, x_{n}\right)=0
$$

It then follows from Lemma 1.9 that $\left\|x_{m}-x_{n}\right\| \rightarrow 0$ as $m, n \rightarrow \infty$. Hence, $\left\{x_{n}\right\}_{n=0}^{\infty}$ is a Cauchy sequence. Since $E$ is a Banach space and $C$ is closed and convex, there exists $p \in C$ such that $x_{n} \rightarrow p$ as $n \rightarrow \infty$.

Now since $\phi\left(x_{m}, x_{n}\right) \rightarrow 0$ as $m, n \rightarrow \infty$ we have in particular that $\phi\left(x_{n+1}, x_{n}\right) \rightarrow 0$ as $n \rightarrow \infty$ and this further implies that $\lim _{n \rightarrow \infty}\left\|x_{n+1}-x_{n}\right\|=0$. Since $x_{n+1}=\Pi_{C_{n=1}}^{f} x_{0} \in C_{n+1}$ we have

$$
\phi\left(x_{n+1}, u_{n}\right) \leq \phi\left(x_{n+1}, x_{n}\right), \quad \forall n \geq 0 .
$$

Then we obtain

$$
\lim _{n \rightarrow \infty} \phi\left(x_{n+1}, u_{n}\right)=0
$$

Since $E$ is uniformly convex and smooth, we have from Lemma 1.9

$$
\lim _{n \rightarrow \infty}\left\|x_{n+1}-x_{n}\right\|=0=\lim _{n \rightarrow \infty}\left\|x_{n+1}-u_{n}\right\| .
$$

So,

$$
\left\|x_{n}-u_{n}\right\| \leq\left\|x_{n+1}-x_{n}\right\|+\left\|x_{n+1}-u_{n}\right\| .
$$


Hence,

$$
\lim _{n \rightarrow \infty}\left\|x_{n}-u_{n}\right\|=0
$$

Since $J$ is uniformly norm-to-norm continuous on bounded sets and $\lim _{n \rightarrow \infty}\left\|x_{n}-u_{n}\right\|=0$, we obtain

$$
\lim _{n \rightarrow \infty}\left\|J x_{n}-J u_{n}\right\|=0
$$

Let $r=\sup _{n \geq 1}\left\{\left\|x_{n}\right\|,\left\|T_{n} x_{n}\right\|\right\}$. Since $E$ is uniformly smooth, we know that $E^{*}$ is uniformly convex. Then from Lemma 1.10, we have

$$
\begin{aligned}
G\left(x^{*}, J u_{n}\right)= & G\left(x^{*}, J \theta_{n}^{m} y_{n}\right) \leq G\left(x^{*}, J y_{n}\right) \\
= & G\left(x^{*},\left(\alpha_{n} J x_{n}+\left(1-\alpha_{n}\right) J T_{n} x_{n}\right)\right) \\
= & \left\|x^{*}\right\|^{2}-2 \alpha_{n}\left\langle x^{*}, J x_{n}\right\rangle-2\left(1-\alpha_{n}\right)\left\langle x^{*}, J T_{n} x_{n}\right\rangle \\
& +\left\|\alpha_{n} J x_{n}+\left(1-\alpha_{n}\right) J T_{n} x_{n}\right\|^{2}+2 \rho f\left(x^{*}\right) \\
\leq & \left\|x^{*}\right\|^{2}-2 \alpha_{n}\left\langle x^{*}, J x_{n}\right\rangle-2\left(1-\alpha_{n}\right)\left\langle x^{*}, J T_{n} x_{n}\right\rangle \\
& +\alpha_{n}\left\|J x_{n}\right\|^{2}+\left(1-\alpha_{n}\right)\left\|J T_{n} x_{n}\right\|^{2} \\
& -\alpha_{n}\left(1-\alpha_{n}\right) g\left(\left\|J x_{n}-J T_{n} x_{n}\right\|\right)+2 \rho f\left(x^{*}\right) \\
= & \alpha_{n} G\left(x^{*}, J x_{n}\right)+\left(1-\alpha_{n}\right) G\left(x^{*}, J T_{n} x_{n}\right) \\
& -\alpha_{n}\left(1-\alpha_{n}\right) g\left(\left\|J x_{n}-J T_{n} x_{n}\right\|\right) \\
\leq & G\left(x^{*}, J x_{n}\right)-\alpha_{n}\left(1-\alpha_{n}\right) g\left(\left\|J x_{n}-J T_{n} x_{n}\right\|\right) .
\end{aligned}
$$

It then follows that

$$
\alpha_{n}\left(1-\alpha_{n}\right) g\left(\left\|J x_{n}-J T_{n} x_{n}\right\|\right) \leq G\left(x^{*}, J x_{n}\right)-G\left(x^{*}, J u_{n}\right)
$$

But

$$
\begin{aligned}
G\left(x^{*}, J x_{n}\right)-G\left(x^{*}, J u_{n}\right) & =\left\|x_{n}\right\|^{2}-\left\|u_{n}\right\|^{2}-2\left|x^{*}, J x_{n}-J u_{n}\right\rangle \\
& \leq\left\|x_{n}\right\|^{2}-\left\|u_{n}\right\|^{2}+2\left|\left\langle x^{*}, J x_{n}-J u_{n}\right\rangle\right| \\
& \leq\left|\left\|x_{n}\right\|-\left\|u_{n}\right\|\right|\left(\left\|x_{n}\right\|+\left\|u_{n}\right\|\right)+2\left\|x^{*}\right\|\left\|J x_{n}-J u_{n}\right\| \\
& \leq\left\|x_{n}-u_{n}\right\|\left(\left\|x_{n}\right\|+\left\|u_{n}\right\|\right)+2\left\|x^{*}\right\|\left\|J x_{n}-J u_{n}\right\| .
\end{aligned}
$$

From (2.5) and (2.6), we obtain

$$
G\left(x^{*}, J x_{n}\right)-G\left(x^{*}, J u_{n}\right) \rightarrow 0, \quad n \rightarrow \infty .
$$

Using the condition $\liminf _{n \rightarrow \infty} \alpha_{n}\left(1-\alpha_{n}\right)>0$, we have

$$
\lim _{n \rightarrow \infty} g\left(\left\|J x_{n}-J T_{n} x_{n}\right\|\right)=0 .
$$


By the properties of $g$, we have $\lim _{n \rightarrow \infty}\left\|J x_{n}-J T_{n} x_{n}\right\|=0$. Since $J^{-1}$ is also uniformly normto-norm continuous on bounded sets, we have

$$
\lim _{n \rightarrow \infty}\left\|x_{n}-T_{n} x_{n}\right\|=0
$$

Since $\left\{T_{n}\right\}_{n=1}^{\infty}$ are uniformly closed, and $\left\{x_{n}\right\}_{n=1}^{\infty}$ is a Cauchy sequence. Then $p \in F(T)=$ $\bigcap_{n=1}^{\infty} F\left(T_{n}\right)$.

Next, we show that $p \in \bigcap_{k=1}^{m} E P\left(F_{k}\right)$. From (2.1), we obtain

$$
\begin{aligned}
\phi\left(x^{*}, u_{n}\right) & =\phi\left(x^{*}, \theta_{n}^{m} y_{n}\right)=\phi\left(x^{*}, T_{r_{m, n}}^{F_{m}} \theta_{n}^{m-1} y_{n}\right) \\
& \leq \phi\left(x^{*}, \theta_{n}^{m-1} y_{n}\right) \leq \phi\left(x^{*}, x_{n}\right) .
\end{aligned}
$$

Since $x^{*} \in E P\left(F_{m}\right)=F\left(T_{r_{m, n}}^{F_{m}}\right)$ for all $n \geq 1$, it follows from (2.7) and Lemma 1.13 that

$$
\begin{aligned}
\phi\left(u_{n}, \theta_{n}^{m-1} y_{n}\right) & =\phi\left(T_{r_{m, n}}^{F_{m}} \theta_{n}^{m-1} y_{n}, \theta_{n}^{m-1} y_{n}\right) \\
& \leq \phi\left(x^{*}, \theta_{n}^{m-1} y_{n}\right)-\phi\left(x^{*}, u_{n}\right) \leq \phi\left(x^{*}, x_{n}\right)-\phi\left(x^{*}, u_{n}\right) .
\end{aligned}
$$

From (2.5) and (2.6), we obtain $\lim _{n \rightarrow \infty} \phi\left(\theta_{n}^{m} y_{n}, \theta_{n}^{m-1} y_{n}\right)=\lim _{n \rightarrow \infty} \phi\left(u_{n}, \theta_{n}^{m-1} y_{n}\right)=0$. From Lemma 1.9, we have

$$
\lim _{n \rightarrow \infty}\left\|\theta_{n}^{m} y_{n}-\theta_{n}^{m-1} y_{n}\right\|=\lim _{n \rightarrow \infty}\left\|u_{n}-\theta_{n}^{m-1} y_{n}\right\|=0
$$

Hence, we have from (2.8) that

$$
\lim _{n \rightarrow \infty}\left\|J \theta_{n}^{m} y_{n}-J \theta_{n}^{m-1} y_{n}\right\|=0 .
$$

Again, since $x^{*} \in E P\left(F_{m-1}\right)=F\left(T_{r_{m-1, n}}^{F_{m-1}}\right)$ for all $n \geq 1$, it follows from (2.7) and Lemma 1.13 that

$$
\begin{aligned}
\phi\left(\theta_{n}^{m-1} y_{n}, \theta_{n}^{m-2} y_{n}\right) & =\phi\left(T_{r_{m-1, n}}^{F_{m-1}} \theta_{n}^{m-2} y_{n}, \theta_{n}^{m-2} y_{n}\right) \\
& \leq \phi\left(x^{*}, \theta_{n}^{m-2} y_{n}\right)-\phi\left(x^{*}, \theta_{n}^{m-1} y_{n}\right) \leq \phi\left(x^{*}, x_{n}\right)-\phi\left(x^{*}, u_{n}\right) .
\end{aligned}
$$

Again, from (2.5) and (2.6), we obtain $\lim _{n \rightarrow \infty} \phi\left(\theta_{n}^{m-1} y_{n}, \theta_{n}^{m-2} y_{n}\right)=0$. From Lemma 1.9, we have

$$
\lim _{n \rightarrow \infty}\left\|\theta_{n}^{m-1} y_{n}-\theta_{n}^{m-2} y_{n}\right\|=0
$$

and hence,

$$
\lim _{n \rightarrow \infty}\left\|J \theta_{n}^{m-1} y_{n}-J \theta_{n}^{m-2} y_{n}\right\|=0
$$

In a similar way, we can verify that

$$
\lim _{n \rightarrow \infty}\left\|\theta_{n}^{m-2} y_{n}-\theta_{n}^{m-3} y_{n}\right\|=\cdots=\lim _{n \rightarrow \infty}\left\|\theta_{n}^{1} y_{n}-y_{n}\right\|=0 .
$$


From (2.8), (2.10), and (2.12), we can conclude that

$$
\lim _{n \rightarrow \infty}\left\|\theta_{n}^{k} y_{n}-\theta_{n}^{k-1} y_{n}\right\|=0, \quad k=1,2, \ldots, m .
$$

Since $x_{n} \rightarrow p, n \rightarrow \infty$, we obtain from (2.5) that $u_{n} \rightarrow p, n \rightarrow \infty$. Again, from (2.8), (2.10), (2.12), and $u_{n} \rightarrow p, n \rightarrow \infty$, we have that $\theta_{n}^{k} y_{n} \rightarrow p, n \rightarrow \infty$ for each $k=1,2, \ldots, m$. Also, using (2.13), we obtain

$$
\lim _{n \rightarrow \infty}\left\|J \theta_{n}^{k} y_{n}-J \theta_{n}^{k-1} y_{n}\right\|=0, \quad k=1,2, \ldots, m .
$$

Since $\liminf _{n \rightarrow \infty} r_{k, n}>0, k=1,2, \ldots, m$,

$$
\lim _{n \rightarrow \infty} \frac{\left\|J \theta_{n}^{k} y_{n}-J \theta_{n}^{k-1} y_{n}\right\|}{r_{k, n}}=0 .
$$

By Lemma 1.12, we have for each $k=1,2, \ldots, m$

$$
F_{k}\left(\theta_{n}^{k} y_{n}, y\right)+\frac{1}{r_{k, n}}\left\langle y-\theta_{n}^{k} y_{n}, J \theta_{n}^{k} y_{n}-J \theta_{n}^{k-1} y_{n}\right\rangle \geq 0, \quad \forall y \in C .
$$

Furthermore, using (A2) we obtain

$$
\frac{1}{r_{k, n}}\left\langle y-\theta_{n}^{k} y_{n}, J \theta_{n}^{k} y_{n}-J \theta_{n}^{k-1} y_{n}\right\rangle \geq F_{k}\left(y, \theta_{n}^{k} y_{n}\right) .
$$

By (A4), (2.14), and $\theta_{n}^{k} y_{n} \rightarrow p$, we have for each $k=1,2, \ldots, m$

$$
F_{k}(y, p) \leq 0, \quad y \in C
$$

For fixed $y \in C$, let $z_{t}=t y+(1-t) p$ for all $t \in(0,1]$. This implies that $z_{t} \in C$. This yields $F_{k}\left(z_{t}, p\right) \leq 0$. It follows from (A1) and (A4) that

$$
0=F_{k}\left(z_{t}, z_{t}\right) \leq t F_{k}\left(z_{t}, y\right)+(1-t) F_{k}\left(z_{t}, p\right) \leq t F_{k}\left(z_{t}, y\right)
$$

and hence

$$
0 \leq F_{k}\left(z_{t}, y\right)
$$

From condition (A3), we obtain

$$
F_{k}(p, y) \geq 0, \quad y \in C .
$$

This implies that $p \in E P\left(F_{k}\right), k=1,2, \ldots, m$. Thus, $p \in \bigcap_{k=1}^{m} E P\left(F_{k}\right)$. Hence, we have $p \in$ $F=\bigcap_{k=1}^{m} E P\left(F_{k}\right) \cap\left(\bigcap_{n=1}^{\infty} F\left(T_{n}\right)\right)$.

Finally, we show that $p=\Pi_{F}^{f} x_{0}$. Since $F=\bigcap_{k=1}^{m} E P\left(F_{k}\right) \cap\left(\bigcap_{n=1}^{\infty} F\left(T_{n}\right)\right)$ is a closed and convex set, from Lemma 1.6, we know that $\Pi_{F}^{f} x_{0}$ is single valued and denote $w=\Pi_{F}^{f} x_{0}$. Since $x_{n}=\Pi_{c_{n}}^{f} x_{0}$ and $w \in F \subset C_{n}$, we have

$$
G\left(x_{n}, J x_{0}\right) \leq G\left(w, J x_{0}\right), \quad \forall n \geq 0 .
$$


We know that $G(\xi, J \varphi)$ is convex and lower semi-continuous with respect to $\xi$ when $\varphi$ is fixed. This implies that

$$
G\left(p, J x_{0}\right) \leq \liminf _{n \rightarrow \infty} G\left(x_{n}, J x_{0}\right) \leq \limsup _{n \rightarrow \infty} G\left(x_{n}, J x_{0}\right) \leq G\left(w, J x_{0}\right)
$$

From the definition of $\Pi_{F}^{f} x_{0}$ and $p \in F$, we see that $p=w$. This completes the proof.

Corollary 2.6 Let E be a uniformly convex and uniformly smooth real Banach space, and let $C$ be a nonempty closed convex subset of $E$. For each $k=1,2, \ldots, m$, let $F_{k}$ be a bifunction from $C \times C$ satisfying (A1)-(A4) and let $\left\{T_{n}\right\}_{n=1}^{\infty}$ be a countable family of uniformly closed relatively quasi-nonexpansive mappings of $C$ into itself such that $F:=$ $\left(\bigcap_{n=1}^{\infty} F\left(T_{n}\right)\right) \cap\left(\bigcap_{k=1}^{m} E P\left(F_{k}\right)\right) \neq \emptyset$. Suppose $\left\{x_{n}\right\}_{n=0}^{\infty}$ is iteratively generated by $x_{0} \in C, C_{1}=C$, $x_{1}=\Pi_{C_{1}}^{f} x_{0}$,

$$
\left\{\begin{array}{l}
y_{n}=J^{-1}\left(\alpha_{n} J x_{n}+\left(1-\alpha_{n}\right) J T_{n} x_{n}\right), \\
u_{n}=T_{r_{m, n}}^{F_{m}} T_{r_{m-1, n}}^{F_{m-1}} \cdots T_{r_{2, n}}^{F_{2}} T_{r_{1, n}}^{F_{1}} y_{n}, \\
C_{n+1}=\left\{w \in C_{n}: \phi\left(w, u_{n}\right) \leq \phi\left(w, x_{n}\right)\right\}, \\
x_{n+1}=\Pi_{C_{n+1}} x_{0}, \quad n \geq 1,
\end{array}\right.
$$

where $J$ is the duality mapping on E. Suppose $\left\{\alpha_{n}\right\}_{n=1}^{\infty}$ is a sequence in $(0,1)$ such that $\liminf _{n \rightarrow \infty} \alpha_{n}\left(1-\alpha_{n}\right)>0$, and $\left\{r_{k, n}\right\}_{n=1}^{\infty} \subset(0, \infty)(k=1,2, \ldots, m)$ satisfying $\liminf _{n \rightarrow \infty} r_{k, n}>$ $0(k=1,2, \ldots, m)$. Then $\left\{x_{n}\right\}_{n=0}^{\infty}$ converges strongly to $\Pi_{F} x_{0}$.

Proof Take $f(x)=0$ for all $x \in E$ in Theorem 2.5, then $G(\xi, J x)=\phi(\xi, x)$ and $\Pi_{C}^{f} x_{0}=\Pi_{C} x_{0}$. Then Corollary 2.6 holds.

Take $F_{k} \equiv 0(k=1,2, \ldots, m)$, it is obvious that the following holds.

Corollary 2.7 Let E be a uniformly convex and uniformly smooth real Banach space, and let $C$ be a nonempty closed convex subset of $E$. Let $\left\{T_{n}\right\}_{n=1}^{\infty}$ be a countable family of uniformly closed relatively quasi-nonexpansive mappings of C into itself such that $F=\left(\bigcap_{n=1}^{\infty} F\left(T_{n}\right)\right) \neq$ $\emptyset$. Let $f: E \rightarrow R$ be a convex and lower semi-continuous mapping with $C \subset \operatorname{int}(D(f))$ and suppose $\left\{x_{n}\right\}_{n=0}^{\infty}$ is iteratively generated by $x_{0} \in C, C_{1}=C, x_{1}=\Pi_{C_{1}}^{f} x_{0}$,

$$
\left\{\begin{array}{l}
y_{n}=J^{-1}\left(\alpha_{n} J x_{n}+\left(1-\alpha_{n}\right) J T_{n} x_{n}\right), \\
C_{n+1}=\left\{w \in C_{n}: G\left(w, J y_{n}\right) \leq G\left(w, J x_{n}\right)\right\} \\
x_{n+1}=\Pi_{C_{n+1}}^{f} x_{0}, \quad n \geq 1,
\end{array}\right.
$$

where $J$ is the duality mapping on E. Suppose $\left\{\alpha_{n}\right\}_{n=1}^{\infty}$ is a sequence in $(0,1)$ such that $\liminf _{n \rightarrow \infty} \alpha_{n}\left(1-\alpha_{n}\right)>0$, and $\left\{r_{k, n}\right\}_{n=1}^{\infty} \subset(0, \infty)(k=1,2, \ldots, m)$ satisfying $\liminf _{n \rightarrow \infty} r_{k, n}>$ $0(k=1,2, \ldots, m)$. Then $\left\{x_{n}\right\}_{n=0}^{\infty}$ converges strongly to $\Pi_{F} x_{0}$.

\section{Applications}

Let $\varphi: C \rightarrow R$ be a real-valued function. The convex minimization problem is to find $x^{*} \in C$ such that

$$
\varphi\left(x^{*}\right) \leq \varphi(y)
$$


$\forall y \in C$. The set of solutions of (3.1) is denoted by $C M P(\varphi)$. For each $r>0$ and $x \in E$, define the mapping

$$
T_{r}^{\varphi}(x)=\left\{z \in C: \varphi(y)+\frac{1}{r}\langle y-z, J z-J x\rangle \geq \varphi(z), \forall y \in C\right\} .
$$

Theorem 3.1 Let E be a uniformly convex and uniformly smooth real Banach space, and let $C$ be a nonempty closed convex subset of $E$. For each $k=1,2, \ldots, m$, let $\varphi_{k}$ be a bifunction from $C \times C$ satisfying (A1)-(A4) and let $\left\{T_{n}\right\}_{n=1}^{\infty}$ be a countable family of uniformly closed relatively quasi-nonexpansive mappings of $C$ into itself such that $F:=$ $\left(\bigcap_{n=1}^{\infty} F\left(T_{n}\right)\right) \cap\left(\bigcap_{k=1}^{m} C M P\left(\varphi_{k}\right)\right) \neq \emptyset$. Let $f: E \rightarrow R$ be a convex and lower semi-continuous mapping with $C \subset \operatorname{int}(D(f))$ and suppose $\left\{x_{n}\right\}_{n=0}^{\infty}$ is iteratively generated by $x_{0} \in C, C_{1}=C$, $x_{1}=\Pi_{C_{1}}^{f} x_{0}$,

$$
\left\{\begin{array}{l}
y_{n}=J^{-1}\left(\alpha_{n} J x_{n}+\left(1-\alpha_{n}\right) J T_{n} x_{n}\right), \\
u_{n}=T_{r_{m, n}}^{\varphi_{m}} T_{r_{m-1, n}}^{\varphi_{m-1}} \cdots T_{r_{2, n}}^{\varphi_{2}} T_{r_{1, n}}^{\varphi_{1}} y_{n}, \\
C_{n+1}=\left\{w \in C_{n}: G\left(w, J u_{n}\right) \leq G\left(w, J x_{n}\right)\right\} \\
x_{n+1}=\Pi_{C_{n+1}}^{f} x_{0}, \quad n \geq 1,
\end{array}\right.
$$

where $J$ is the duality mapping on E. Suppose $\left\{\alpha_{n}\right\}_{n=1}^{\infty}$ is a sequence in $(0,1)$ such that $\liminf _{n \rightarrow \infty} \alpha_{n}\left(1-\alpha_{n}\right)>0$ and $\left\{r_{k, n}\right\}_{n=1}^{\infty} \subset(0, \infty)(k=1,2, \ldots, m)$ satisfying $\liminf _{n \rightarrow \infty} r_{k, n}>$ $0(k=1,2, \ldots, m)$. Then $\left\{x_{n}\right\}_{n=0}^{\infty}$ converges strongly to $\Pi_{F}^{f} x_{0}$.

Proof Define $F_{k}(x, y)=\varphi_{k}(y)-\varphi_{k}(x), x, y \in C$ and $k=1,2, \ldots, m$. Then $F\left(T_{r_{k}}^{F_{k}}\right)=E P\left(F_{k}\right)=$ $\operatorname{CMP}\left(\varphi_{k}\right)=F\left(T_{r_{k}}^{\varphi_{k}}\right)$ for each $k=1,2, \ldots, m$, and therefore $\left\{F_{k}\right\}_{k=1}^{m}$ satisfies conditions (A1) and (A2). Furthermore, one can easily show that $\left\{F_{k}\right\}_{k=1}^{m}$ satisfies (A3) and (A4). Therefore, from Theorem 2.5, we obtain Theorem 3.1.

\section{Competing interests}

The authors declare that they have no competing interests.

\section{Authors' contributions}

All authors contributed equally and significantly in writing this article. All authors read and approved the final manuscript.

\section{Acknowledgements}

This project is supported by the National Natural Science Foundation of China under grant (11071279).

Received: 9 February 2014 Accepted: 31 March 2014 Published: 06 May 2014

\section{References}

1. Butnariu, D, Reich, S, Zaslavski, AJ: Asymptotic behaviour of relatively nonexpansive operators in Banach spaces. J. Appl. Anal. 7, 151-174 (2001)

2. Butnariu, D, Reich, S, Zaslavski, AJ: Weak convergence of orbits of nonlinear operator in reflexive Banach spaces Numer. Funct. Anal. Optim. 24, 489-508 (2003)

3. Censor, Y, Reich, S: Iterations of paracontractions and firmly nonexpansive operators with applications to feasibility and optimization. Optimization 37, 323-339 (1996)

4. Matsushita, S, Takahashi, W: A strong convergence theorem for relatively nonexpansive mappings in Banach spaces. J. Approx. Theory 134, 257-266 (2005)

5. Chidume, CE: Geometric Properties of Banach Spaces and Nonlinear Iterations. Lecture Notes in Mathematics, vol. 1965. Springer, Berlin (2009). ISBN:978-1-84882-189-7. xviii+326 pp.

6. Takahashi, W: Nonlinear Functional Analysis-Fixed Point Theory and Applications. Yokohama Publishers, Yokohama (2000) (in Japanese)

7. Takahashi, W: Nonlinear Functional Analysis. Yokohama Publishers, Yokohama (2000)

8. Alber, Yl: Metric and generalized projection operator in Banach spaces: properties and applications. In: Theory and Applications of Nonlinear Operators of Accretive and Monotone Type. Lecture Notes in Pure and Applied Mathematics, vol. 178, pp. 15-50. Dekker, New York (1996) 
9. $\mathrm{Wu}, \mathrm{KQ}$, Huang, NJ: The generalized $f$-projection operator with application. Bull. Aust. Math. Soc. 73, 307-317 (2006)

10. Fan, JH, Liu, X, Li, JL: Iterative schemes for approximating solutions of generalized variational inequalities in Banach spaces. Nonlinear Anal. 70, 3997-4007 (2009)

11. Shehu, Y: Strong convergence theorems for infinite family of relatively quasi-nonexpansive mappings and systems of equilibrium problems. Appl. Math. Comput. 218, 5146-5156 (2012)

12. Deimling, K: Nonlinear Functional Analysis. Springer, Berlin (1985)

13. Li, X, Huang, N, O'Regan, D: Strong convergence theorems for relatively nonexpansive mappings in Banach spaces with applications. Comput. Math. Appl. 60, 1322-1331 (2010)

14. Qin, X, Cho, YJ, Kang, SM: Convergence theorems of common elements for equilibrium problems and fixed point problems in Banach spaces. J. Comput. Appl. Math. 225, 20-30 (2009)

15. Nilsrakoo, W, Saejung, S: Strong convergence to common fixed points of countable relatively quasi-nonexpansive mappings. Fixed Point Theory Appl. 2008, Article ID 312454 (2008)

16. Kamimura, S, Takahashi, W: Strong convergence of a proximal-type algorithm in a Banach space. SIAM J. Optim. 13 938-945 (2002)

17. Xu, HK: Inequalities in Banach spaces with applications. Nonlinear Anal. 16(2), 1127-1138 (1991)

18. Blum, E, Oettli, W: From optimization and variational inequalities to equilibrium problems. Math. Stud. 63, 123-145 (1994)

19. Takahashi, W, Zembayashi, K: Strong and weak convergence theorems for equilibrium problems and relatively nonexpansive mappings in Banach spaces. Nonlinear Anal. 70, 45-57 (2009)

10.1186/1687-1812-2014-103

Cite this article as: Zhang et al.: Uniformly closed replaced AKTT or *AKTT condition to get strong convergence theorems for a countable family of relatively quasi-nonexpansive mappings and systems of equilibrium problems. Fixed Point Theory and Applications 2014, 2014:103

\section{Submit your manuscript to a SpringerOpen ${ }^{\circ}$ journal and benefit from:}

- Convenient online submission

- Rigorous peer review

- Immediate publication on acceptance

- Open access: articles freely available online

- High visibility within the field

- Retaining the copyright to your article 